\title{
Feasibility of a Combined Mobile-Health Electrocardiographic and Rapid Diagnostic Test Screening for Chagas-Related Cardiac Alterations
}

\author{
Michele Spinicci ${ }^{1,2,+}{ }^{D}$, Carlo Fumagalli ${ }^{1,3,+}{ }^{,}$Niccolò Maurizi ${ }^{3,4}$, Enrico Guglielmi ${ }^{1}$, Mimmo Roselli ${ }^{1}$ (D), \\ Herlan Gamboa ${ }^{5}$, Marianne Strohmeyer ${ }^{1}$, Veronica Poma ${ }^{6}$, Roberto Vargas ${ }^{7}$, Iacopo Olivotto ${ }^{1,3, *(D)}$ \\ and Alessandro Bartoloni 1,2,*(D)
}

Citation: Spinicci, M.; Fumagalli, C.; Maurizi, N.; Guglielmi, E.; Roselli, M.; Gamboa, H.; Strohmeyer, M.; Poma,

V.; Vargas, R.; Olivotto, I.; et al. Feasibility of a Combined

Mobile-Health Electrocardiographic and Rapid Diagnostic Test Screening for Chagas-Related Cardiac Alterations. Microorganisms 2021, 9 , 1889. https://doi.org/10.3390/ microorganisms 9091889

Academic Editor: Pat Nuttall

Received: 22 July 2021

Accepted: 30 August 2021

Published: 6 September 2021

Publisher's Note: MDPI stays neutral with regard to jurisdictional claims in published maps and institutional affiliations.

Copyright: (C) 2021 by the authors. Licensee MDPI, Basel, Switzerland. This article is an open access article distributed under the terms and conditions of the Creative Commons Attribution (CC BY) license (https:// creativecommons.org/licenses/by/ $4.0 /)$.
1 Department of Experimental and Clinical Medicine, University of Florence, 50134 Florence, Italy; michele.spinicci@unifi.it (M.S.); carlo.fumagalli@unifi.it (C.F.); guglielmi75@yahoo.it (E.G.); mimrose@hotmail.com (M.R.); marianne.strohmeyer@unifi.it (M.S.)

2 Infectious and Tropical Diseases Unit, Careggi University Hospital, 50134 Florence, Italy

3 Cardiomyopathy Unit, Cardiothoracic and Vascular Department, Careggi University Hospital, 50134 Florence, Italy; niccolo.maurizi@gmail.com

4 Cardiology Service, University Hospital of Lausanne, CH-1011 Lausanne, Switzerland

5 Facultad Integral del Chaco, Universidad Autónoma Gabriel René Moreno, Camiri, Bolivia; herlan.gamboa@hotmail.com

6 Escuela de Salud del Chaco Tekove Katu, Gutierrez, Bolivia; kollita2009@hotmail.com

7 Programa Nacional de Chagas, Ministerio de Salud, La Paz, Bolivia; sedessantacruz@hotmail.com

* Correspondence: iacopo.olivotto@unifi.it (I.O.); alessandro.bartoloni@unifi.it (A.B.)

+ Authors contributed equally to the work.

Abstract: Background: Chronic Chagas cardiomyopathy (CChC) is the most common cause of death related to Chagas disease (CD). The aim of this study was to assess the feasibility of a combined rapid diagnostic test (RDT) and electrocardiographic (ECG) screening in a remote rural village of the Bolivian Chaco, with a high prevalence of CChC. Methods: Consecutive healthy volunteers $>15$ years were enrolled in the community of Palmarito (municipality of Gutierrez, Santa Cruz Department, Bolivia) in February 2019. All patients performed an RDT with Chagas Stat-Pak ${ }^{\circledR}$ (CSP, Chembio Diagnostic System, Medford, NY, USA) and an ECG by D-Heart ${ }^{\circledR}$ technology, a low-cost, userfriendly smartphone-based 8-lead Bluetooth ECG. RDTs were read locally while ECGs were sent to a cardiology clinic which transmitted reports within $24 \mathrm{~h}$ from recording. Results: Among 140 people (54 men, median age 38(interquartile range 23-54) years), 98 (70\%) were positive for Trypanosoma cruzi infection, with a linear, age-dependent, increasing trend $(p<0.001)$. Twenty-five $(18 \%)$ individuals showed ECG abnormalities compatible with CD. Prevalence of ECG abnormalities was higher in infected individuals and was associated with higher systolic blood pressure and smoking. Following screening, 22 (16\%) individuals underwent clinical evaluation and chest X-ray and two were referred for further evaluation. At multivariate analysis, positive CSP results (OR $=4.75,95 \%$ CI 1.08-20.96, $p=0.039)$ and smoking (OR $=4.20,95 \%$ CI 1.18-14.92, $p=0.027)$ were independent predictors of ECG abnormalities. Overall cost for screening implementation was $<10 \$$. Conclusions: Combined mobile-Health and RDTs was a reliable and effective low-cost strategy to identify patients at high risk of disease needing cardiologic assessment suggesting potential future applications.

Keywords: Chagas disease; Chagas Stat-Pak; chronic Chagas cardiomyopathy; mHealth; telemedicine; seroprevalence; Bolivia; Chaco

\section{Introduction}

Chagas disease (CD), caused by infection with the protozoan parasite Trypanosoma cruzi, is the neglected tropical disease exerting the highest burden in most Latin American countries, with 8 million persons chronically infected and approximately 200,000 new cases 
each year [1]. It is transmitted to humans through the feces of infected hematophagous triatomine insects in areas in which the disease is endemic and, occasionally, by nonvectorial mechanisms such as blood transfusion, organ transplants, or vertically from mother-to-child [2].

Three clinical stages of $\mathrm{CD}$ have been described: the acute phase, typically asymptomatic and short-lasting, followed by a chronic long-acting phase that may span for decades without showing any symptoms associated to the infection (indeterminate stage), and the determinate phase. Approximately $40 \%$ of chronically infected individuals progress to either advanced cardiac and / or digestive tract forms characterized by high morbidity and mortality, if left untreated [2].

Despite progress in vector control [3,4], a timely and accurate diagnosis remains a major obstacle to start treatment. Still today, early accessing to presently available drugs is a major issue. It is estimated that current chemotherapies only reach $1 \%$ of infected individuals $[1,5]$.

Communities with intense transmission remain, especially in the Bolivian Gran Chaco (estimated infection rate at $4 \%$ per year) [3,4]. Cardiac involvement, i.e., Chagas Cardiomyopathy $(\mathrm{CChC})$, is the main cause of death $[2,5,6]$. The early signs of Chagas cardiomyopathy are typically conduction system abnormalities, most commonly right bundle branch block (RBBB), often progressing to bifascicular blocks. Later manifestations include left ventricular systolic dysfunction, apical aneurysms, high-degree atrioventricular block, and sustained and non-sustained ventricular tachycardia [6-8]. Of note, sudden cardiac death may occur at any moment, including early phases. Therefore, early recognition of cardiac involvement through cost-effective screening efforts becomes a priority in areas with high endemic burden. As patients with $C D$, compared to non-CD subjects, have almost a threefold higher prevalence of electrocardiogram (ECG) alterations, ECG coupled with a rapid diagnostic test (RDT) screening can be a reasonable first-line approach. However, limited resources, lack of trained personnel and infrastructures in highly endemic areas, challenge the implementation of such programs. Smartphone technology, with its' computational power, applied to telemedicine may overcome several of these limitations by providing an easy and affordable access to accurate diagnostic methods [9-11].

The aim of this study was to understand the potential impact and sustainability of a mHealth ECG screening program, coupled with an RDT test, in remote rural villages of the Bolivian Chaco with the help of a validated smartphone-based ECG (D-Heart $\left.{ }^{\circledR}\right)$. The present device allows low-cost ECG screening campaigns by community health workers and offers the possibility of Remote ECG interpretation by expert physicians.

\section{Materials and Methods}

\subsection{Study Population and Settings}

The study was carried out in Palmarito Community (municipality of Gutierrez, Santa Cruz Department; $19^{\circ} 49^{\prime}$ S; $63^{\circ} 48^{\prime}$ W, Bolivian Chaco Region), in February 2019. In this region, estimated seroprevalence of Chagas Disease is $50 \%$ in the general population, but can be as high as $70 \%$ in individuals aged $>15$ years [3,4]. The nearest secondary level Hospital is located $80 \mathrm{~km}$ far away (Hospital Municipal de Camiri). All individuals $\geq 15$ years old were invited to participate to the study. Overall, 653 inhabitants live in Palmarito, of whom 402 people $\geq 15$ years old. A representative sample of 140 healthy volunteers were consecutively enrolled, taking into account the age group distribution. Demographic data was recorded, and a brief clinical history, focused on common cardiovascular risk factors and manifestations, was obtained through a standardized questionnaire. Height and weight were recorded and body mass index (BMI) calculated. All participants underwent blood pressure (BP) measurement, by trained personnel, before performing electrocardiographic and serological screening; those with elevated systolic (SBP $\geq 140 \mathrm{mmHg}$ ) and/or diastolic blood pressure (DBP $\geq 90 \mathrm{mmHg}$ ) had a second measurement. 


\subsection{ECG Screening and Referral Path}

For each participant, an ECG was recorded using D-Heart ${ }^{\circledR}$ electrocardiograph. DHeart $^{\circledR}$ is a CE marked multiple lead smartphone-based ECG device (DI, DII, DIII, aVR, $\mathrm{aVL}, \mathrm{aVF}$ peripheral leads $\mathrm{V} 2$ and $\mathrm{V} 5$ precordial leads) specifically designed for ECG screening in low-income settings by non-medical personnel $[10,11]$. The device is manufactured by the social-vocation start-up D-Heart, an Italian-based company. The device weighs less than $194 \mathrm{~g}$ and is extremely portable. If operated by non-health professionals it can register an 8-lead ECG, whereas in the health professionals setting standard 12-lead ECG can be acquired. The module Bluetooth Low Energy streams the ECG data to the smartphone in a medically certified App that enables in loco reading of the tracings or Telecardiology Reporting via web-based Telecardiology Platform. The actual components of the device offer a manufacturing price of $90 \$$ per unit.

ECG tracings were acquired with D-Heart Smartphone ECG device during the on-site screening activities and were sent daily to the Cardiomyopathy Unit, Careggi Hospital, Florence, Italy where they were read with D-Heart Telecardiology Platform within $24 \mathrm{~h}$ by two staff physicians, N.M and C.F., blinded for subjects' T.cruzi infection status. Each ECG was recorded with a dedicated smartphone protected by a code known by the Community Health Worker. An abnormal ECG suggestive of CChC was defined as an ECG with (i) ventricular conduction defects: complete right BBB (RBBB), left anterior fascicular block, left posterior fascicular block, left bundle branch block, or bifascicular block; (ii) any degree of atrioventricular block; (iii) rhythm disturbances: atrial fibrillation/flutter, junctional rhythm, sinus bradycardia with heart rate $<50$ beats $/ \mathrm{min}$, or complex ventricular ectopy; (iv) other: pathologic $Q$ waves, fragmented QRS, low QRS voltage $[6,7,12]$. Other findings, such as incomplete RBBB, atrial ectopy, nonspecific ST-T wave changes, right or left ventricular hypertrophy were considered nonspecific for $\mathrm{CChC}$ and were not included in our definition of CChC-related ECG abnormality. Reports were sent back daily to the Community Health Center in Palmarito.

\subsection{T. cruzi Infection Screening Chagas Stat-Pak ${ }^{\circledR}$ Assay}

After ECG testing, all patients during the onsite screening activities performed a Chagas Stat-Pak ${ }^{\circledR}$ (CSP) (Chembio Diagnostic System, Medford, NY, USA), an immunochromatographic, qualitative, rapid diagnostic test (RDT), which uses a combination of antigens for the detection of IgG antibodies to T. cruzi, in use as standard tool for Chagas disease screening by the Chagas National Program since 2005. Blood samples were obtained by finger-prick and the result read after $15 \mathrm{~min}$, according to the manufacturer's instructions. During previous studies, carried out in the same highly endemic area of the Bolivian Chaco, CSP yielded excellent performance in comparison with the conventional serology, with sensitivity, specificity, positive predictive value and negative predictive value up to $100 \%$, $99.3 \%, 99.5 \%$, and $100 \%$, respectively [13,14].

\subsection{Sustainability and Cost of a mHealth Screening Campaign}

Financial feasibility models were built to project the overall cost of our screening campaign. A total of two analyses were performed: the first model would include startup and operative costs related to human resources, consumables (RDT kits, electrodes, disinfection kits), non-consumable devices (D-Heart ${ }^{\circledR}$, compatible smartphone, blood pressure cuff, and internet connection) and logistics; the second one would comprise only consumables and human resources for screening continuation.

\subsection{Statistical Analysis}

Statistical analysis of the data was performed with STATA 11.0 (StataCorp, College Statio, TX, USA). Frequencies and percentages with $95 \%$ confidence intervals (CI) for categorical variables, means and medians and interquantile ranges (IQR) for continuous variables were calculated. T-Student test or Mann-Whitney test were used to compare continuous variables. Chi-square test, or Fisher's exact test, when appropriate, were used 
to investigate the association between positive CSP test with ECG abnormalities, individual risk factors and demographic data. Multivariate logistic regression was performed including age, sex and all the variables significantly associated to ECG abnormalities at univariate analysis. Results were considered significant when the $p$-value $\leq 0.05$.

\subsection{Ethics Statement}

The study was realized in agreement with the Ministry of Health of the Plurinational State of Bolivia (Convenio Ministerio de Salud y Deportes, Estado Plurinacional de Bolivia/Cátedra de Enfermedades Infecciosas, Universidad de Florencia, Italia), the Servicio Departamental de Salud (SEDES) of Santa Cruz and with the support of the Guarani political organization (Asamblea del Pueblo Guaraní). The study was approved by a local Ethic Committee and a written informed consent was obtained by each enrolled participant (or by a parent or a legal guardian, if minor).

\section{Results}

\subsection{Baseline Characteristics}

Of the 140 subjects included in the study, 54 (39\%) were men, with a median age of 38 (interquanrtile range 23-54) from 15 to 85 years old. Twenty-four (17\%) had family history for cardiovascular diseases and 11 (8\%) of sudden unexpected death. Cardiovascular risk profile was generally low, with only five (4\%) individuals affected by Type 2 diabetes mellitus, two (1\%) with known dyslipidemia and median BMI was $24 \mathrm{~kg} / \mathrm{m} 2$ (22-27). Palpitations were reported by $39(28 \%)$ patients, whereas chest pain was the most common complaint, present in $82(59 \%)$ patients. History of loss of consciousness was present in $14 \%$ of patients (Table 1 )

Table 1. Characteristics of the surveyed population in a rural community of the Bolivian Chaco by $T$. cruzi infection status.

\begin{tabular}{ccccc}
\hline & $\begin{array}{c}\text { Total } \\
(\boldsymbol{n = 1 4 0 )}\end{array}$ & $\begin{array}{c}\text { Chagas Stat Pak } \\
\text { Negative } \\
(\boldsymbol{n}=\mathbf{4 2})\end{array}$ & $\begin{array}{c}{ }^{\circledR} \\
(\boldsymbol{n}=\mathbf{9 8})\end{array}$ & $\boldsymbol{p}$-Values \\
\hline Sex & $54(39 \%)$ & $22(41 \%)$ & $32(59 \%)$ & \\
Male & $86(61 \%)$ & $20(23 \%)$ & $66(77 \%)$ & $0.028^{*}$ \\
Female & $38.5(23-54)$ & $20(17-30)$ & $45(33-62)$ & $<0.001^{\#}$ \\
\hline Age & $15-85$ & $15-75$ & $15-85$ & \\
Range & 34 & $23(68 \%)$ & $11(32 \%)$ & \\
$15-20$ yo & 63 & $17(27 \%)$ & $46(73 \%)$ & $<0.001^{\S}$ \\
$21-49$ yo & 43 & $2(5 \%)$ & $41(95 \%)$ & $0.010^{\circ}$ \\
$\geq 50$ yo & $111 \pm 16$ & $110 \pm 15$ & $117 \pm 13$ & $0.048^{\circ}$
\end{tabular}

Legend: IQR: interquartile range; yo: year-old; SBP: systolic blood pressure; DBP: diastolic blood pressure;

* Pearson's chi-squared test; ${ }^{\#}$ Mann-Whitney test; ${ }^{\S}$ linear regression; ${ }^{\circ} t$-Student test.

No one had been screened with an ECG or for T. cruzi before the study enrolment.

\subsection{Outcome of Combined T. cruzi and ECG Screening}

Community screening was carried out in 6 days. RDTs were read locally, and results recorded, while ECGs were sent to the Florence Cardiomyopathy Unit and analyzed within $24 \mathrm{~h}$ (average response time: $9 \pm 1 \mathrm{~h}$ ). No ECG recording was lost, and all patients with positive ECG and RDT results combined were actively referred to further evaluation.

Overall, $98(70 \%)$ subjects were screened positive for T.cruzi infection with CSP (Table 2). T. cruzi seroreactive people were significantly older than uninfected ones $(p<0.001)$, with a linear, age-dependent, increasing trend $(p<0.001)$. Ten subjects $(7 \% ; 51$ to 85 years) had elevated BP values: four had arterial hypertension at two successive measures, and 
six had isolated systolic hypertension ( $\mathrm{SBP} \geq 140 \mathrm{mmHg}$, DBP $<90 \mathrm{mmHg}$ ). Of note, only two were aware of their condition. Mean SBP and BDP values were slightly-but significantly-higher in CSP-positive group than in non-reactive people (Table 2).

Table 2. Electrocardiographic findings in T. cruzi infected and uninfected population of a rural community of the Bolivian Chaco.

\begin{tabular}{|c|c|c|c|}
\hline & \multirow{2}{*}{$\begin{array}{c}\text { Total } \\
(n=140)\end{array}$} & \multicolumn{2}{|c|}{ Chagas Stat Pak ${ }^{\circledR}$} \\
\hline & & $\begin{array}{c}\text { Negative } \\
(n=42)\end{array}$ & $\begin{array}{c}\text { Positive } \\
(n=98)\end{array}$ \\
\hline Normal & $115(82 \%)$ & $39(93 \%)$ & $76(78 \%)$ \\
\hline Any CD-related abnormality & $25(18 \%)$ & $3(7 \%)$ & $22(22 \%)$ \\
\hline \multicolumn{4}{|l|}{ Bundle Branch Blocks } \\
\hline Complete right $\mathrm{BBB}$ & $6(4 \%)$ & 0 & $6(6 \%)$ \\
\hline Left anterior fascicular block & $2(1 \%)$ & 0 & $2(2 \%)$ \\
\hline Atrioventricular Blocks & & & \\
\hline I degree atrioventricular block & $3(2 \%)$ & $1(2 \%)$ & $2(2 \%)$ \\
\hline \multicolumn{4}{|l|}{ Rhythm disturbances } \\
\hline Sinus bradycardia & $3(2 \%)$ & $1(2 \%)$ & $2(2 \%)$ \\
\hline Complex ventricular ectopies & $2(1 \%)$ & 0 & $2(2 \%)$ \\
\hline \multicolumn{4}{|l|}{ Other } \\
\hline Pathologic $Q$ waves & $2(1 \%)$ & 0 & $2(2 \%)$ \\
\hline Fragmented QRS & $5(4 \%)$ & $1(2 \%)$ & $4(4 \%)$ \\
\hline Low QRS voltage & $2(1 \%)$ & 0 & $2(2 \%)$ \\
\hline Heart rate $(\mathrm{bpm})( \pm \mathrm{SD})$ & $70 \pm 10$ & $73 \pm 12$ & $69 \pm 9$ \\
\hline PR interval (ms) $( \pm \mathrm{SD})$ & $156 \pm 21$ & $156 \pm 16$ & $159 \pm 22$ \\
\hline QTc interval (ms) ( \pm SD) & $410 \pm 24$ & $408 \pm 25$ & $411 \pm 23$ \\
\hline
\end{tabular}

Legend: CD: Chagas disease; BBB: bundle branch blocks; AVB: atrioventricular block; bpm: beats per minute; $\mathrm{ms}$ : milliseconds; SD: standard deviation.

None of the study participants had performed an ECG test prior to enrolment. A total of $115(82 \%)$ subjects had a normal ECG, while 25/140 (18\%) showed ECG abnormalities, compatible with CD, and prevalence was higher in CSP positive individuals ( $22 \%$ vs. $7 \%, p=0.03$ ). No differences were described for PR and QTc intervals duration. ECG abnormalities included Bundle Branch Blocks $(n=8)$, 1st Degree Atrioventricular blocks $(n=3)$, rhythm disturbances $(n=5)$, pathologic $Q$ waves $(n=2)$, fragmented QRS $(n=5)$, and low QRS voltage $(n=2)$ (Table 2$)$. ECG abnormalities were directly associated with higher systolic blood pressure (117 \pm 13 vs $110 \pm 15, p=0.017)$ and smoking habit (48 vs $26 \%, p=0.030$ ) (Table 3 ). Age- and sex-adjusted multivariate analysis confirmed the association of ECG abnormalities with CSP-positive results (OR: 4.75, 95\%CI 1.08-20.96, $p=0.039$ ) and smoking habit (OR: 4.20,95\%CI 1.18-14.92, $p=0.027$ ). 
Table 3. Characteristics and cardiovascular risk factors of the surveyed population in a rural community of the Bolivian Chaco, by D-Heart ${ }^{\circledR}$ result.

\begin{tabular}{|c|c|c|c|c|}
\hline & \multicolumn{4}{|c|}{ D-Heart ${ }^{\circledR}$ ECG } \\
\hline & $\begin{array}{c}\text { Total } \\
(n=140)\end{array}$ & $\begin{array}{l}\text { Normal } \\
(n=115)\end{array}$ & $\begin{array}{c}\text { Any } \\
\text { Abnormality } \\
(n=25)\end{array}$ & $p$-Value \\
\hline \multicolumn{5}{|l|}{ Sex } \\
\hline Male & $54(39 \%)$ & $44(38 \%)$ & $10(40 \%)$ & $0.871 *$ \\
\hline \multicolumn{5}{|l|}{ Age } \\
\hline Median (IQR) & $38(22-54)$ & $37(20-53)$ & $40(31-59)$ & $0.92^{\#}$ \\
\hline Range & $15-85$ & $15-85$ & $16-83$ & \\
\hline \multicolumn{5}{|l|}{ Chagas Stat Pak ${ }^{\circledR}$} \\
\hline Negative & 42 & $39(34 \%)$ & $3(12 \%)$ & \\
\hline Positive & 98 & $76(66 \%)$ & $22(88 \%)$ & $0.032^{\wedge}$ \\
\hline \multicolumn{5}{|l|}{$\mathrm{CV}$ risk factors } \\
\hline $\begin{array}{c}\text { Family history of CV } \\
\text { diseases }\end{array}$ & $24(17 \%)$ & $22(19 \%)$ & $2(8 \%)$ & $0.247^{\wedge}$ \\
\hline $\begin{array}{c}\text { Family history of sudden } \\
\text { death }\end{array}$ & $11(8 \%)$ & $11(10 \%)$ & 0 & $0.211^{\wedge}$ \\
\hline Positive Smoking History & $42(30 \%)$ & $30(26 \%)$ & $12(48 \%)$ & 0.030 * \\
\hline Dyslipidaemia & $2(1 \%)$ & $1(0.9 \%)$ & $1(4 \%)$ & $0.326^{\wedge}$ \\
\hline Diabetes & $5(4 \%)$ & $4(3.5 \%)$ & $1(4 \%)$ & $0.632^{\wedge}$ \\
\hline History of leg oedema & $54(39 \%)$ & $41(36 \%)$ & $13(52 \%)$ & $0.128 *$ \\
\hline Loss of consciousness & $20(14 \%)$ & $16(14 \%)$ & $4(16 \%)$ & $0.757^{\wedge}$ \\
\hline History of Palpitations & $39(28 \%)$ & $33(29 \%)$ & $6(24 \%)$ & 0.635 * \\
\hline History of Chest pain & $82(59 \%)$ & $66(57.4 \%)$ & $16(64 \%)$ & 0.543 * \\
\hline BMI (IQR) & $24(22-27)$ & $24(22-27)$ & $24(22-28)$ & $0.389^{\#}$ \\
\hline SBP (mmHg) & $111 \pm 16$ & $110 \pm 15$ & $117 \pm 13$ & $0.017^{\circ}$ \\
\hline
\end{tabular}

Legend: CV: Cardiovascular Disease; IQR: Interquartile range; BMI: Body Mass Index; SBP: Systolic Blood

Pressure. * Pearson's chi-squared test; ${ }^{\#}$ Mann-Whitney test; ${ }^{`}$ Fisher's exact test; ${ }^{\circ} t$-Student test.

\subsection{Medical Referral, Feasibility of Current Screening Strategy, and Cost Analysis}

Twenty-two patients with a positive CSP testing and possible CD-related ECG abnormalities were recalled from Palmarito Community and referred to the second level Camiri Hospital, where physical examination and chest X-ray were performed. All 22 patients had CD diagnosis confirmed by Chagatest Lisado ELISA (Wiener Laboratories, Rosario, Argentina), performed at the "Elvira Wunderlich" Health Center, Santa Cruz, Bolivia. Of these, two patients had cardiomegaly on the chest X-ray and were referred to further third level examinations. The first person was a 45-year old man, active smoker with history of chest pain; his ECG showed sinus bradycardia with a RBBB. The second person was a 59-year old woman, with history of palpitations, leg edema, chest pain, and loss of consciousness; at ECG, a RBBB and low voltages were present (Figure 1A-C). People with positive CSP, but normal ECG findings, were referred to the Chagas National Program for serological confirmation and possible benznidazole treatment, and managed according to their guidelines [15]. 
A

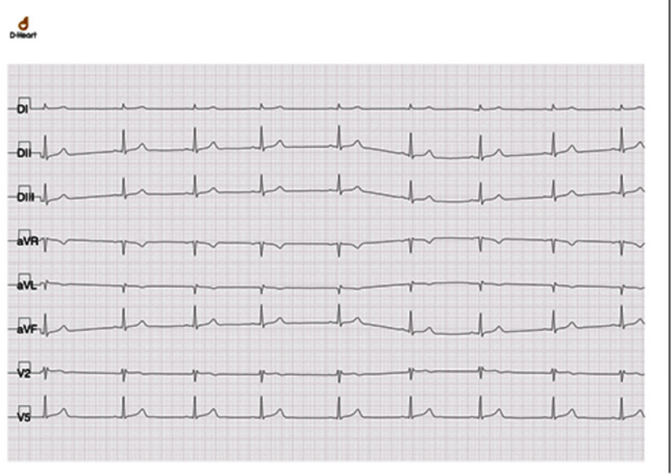

B

$\therefore$

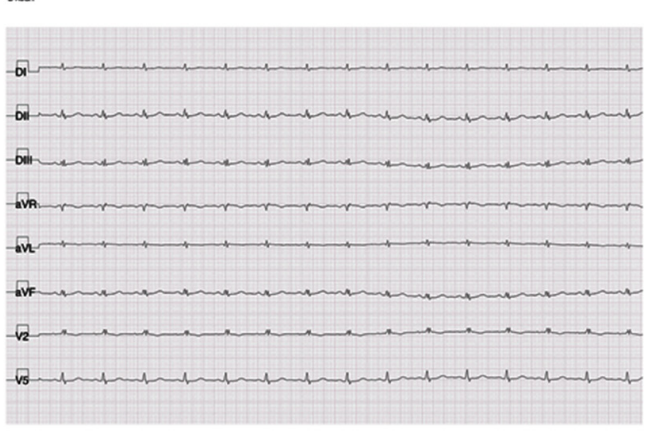

C

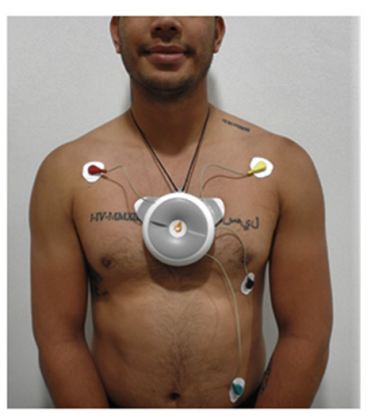

Figure 1. ECG samples of patients referred to further second level examinations and Smartphone ECG device used in the screening activities. (A) 45-year old man, active smoker with history of chest pain; his ECG showed sinus bradycardia with a RBBB; (B) 59-year old woman, with history of palpitations, leg oedema, chest pain and loss of consciousness; at ECG, a RBBB and low voltages were present. (C) Patient during screening activities with D-Heart Smartphone ECG device operating. The D-Heart device can record either 8- or 12-lead ECGs. In the 8-lead setting, DI, DII, and DIII leads are directly measured, as well as precordial unipolar leads V2 and V5. Augmented leads aVR, aVL, and aVF are calculated by definition. In the 12-lead settings, the unipolar electrode in V5 is sequentially placed in V6, V4, V3, V1 position to acquire all the precordial recordings.

Two models for cost effectiveness analysis were developed. The first one, comprising start-up and operative costs, is summarized in Table 4. For a 6-day screening for a community of 150 inhabitants, the overall start-up amount was projected to $4.82 \$$ / patient and to $8.23 \$$ /patient when operative costs (i.e., on-site nurse and healthcare assistant with remote physician on call) were included. For the second model, intended to predict cost of screening continuation, an average of $5.13 \$ /$ patient was estimated.

Table 4. RDT and ECG screening model for 150 Individuals for a 6-day screening.

\begin{tabular}{ccccc}
\hline \multicolumn{2}{c}{ Start Up Cost } & & \\
\hline & Item & Cost/Unit & $\begin{array}{c}\text { Units } \\
\text { Needed }\end{array}$ & $\begin{array}{c}\text { Total Cost } \\
\mathbf{( \$ )}\end{array}$ \\
\hline Consumables & D-Heart & 280 & 1 & 280 \\
& Smartphone & 200 & 1 & 200 \\
Electrodes & 0.12 & 150 & 18 \\
& Blood Pressure Cuff & 20 & 1 & 20 \\
Rdt & 1 & 150 & 150 \\
& Disinfection Kit & 2 & 5 & 10 \\
& Data Plan (Sim Card) 10 GB for & 40 & 1 & 40 \\
& 30 Days & 100 & 1 & 100 \\
& Nurse & 60 & 1 & 60 \\
& Healthcare Assistant & 330 & 1 & 330 \\
& Remote Physician & 11 & 6 & 66 \\
\hline
\end{tabular}

\section{Discussion}

In this study, we evaluated the feasibility of a combined mobile-health electrocardiographic and rapid diagnostic test screening for Chagas-related cardiac alterations in a in a low-income setting, hyperendemic for CD. Subjects screened with ECG were also tested for the presence of T.cruzi antibodies, by an easy-to-use RDT.

In the surveyed community, seroprevalence for T. cruzi was 70\%, and its distribution by age-class was consistent with previously reported data from this $[3,4]$. 
More than one in five patients with CSP positive serology showed ECG abnormalities compatible with CChC $(n=22 / 98,22 \%)$, in line with the estimate that $20-30 \%$ of infected individuals eventually develop heart disease. The most common findings were ventricular conduction defects, including RBBB and left anterior fascicular block. Moreover, we observed a number of ECG with fragmented QRS, considered as a predictor of arrhythmic events in patients with ischemic and non-ischemic cardiomyopathy, previously reported to be highly prevalent among patients with advanced CChC [6,7]. Other abnormalities included AVB and rhythmic disturbances, which are typical CChC manifestations, and low QRS voltage, which has been previously identified as a strong predictor of the risk of death from cardiac causes in CD patients [12].

Notably, 2 of the 22 individuals with positive ECG and CSP were referred for further medical evaluation: in both cases, ECG showed at least two alterations and chest X-ray was abnormal. Multiple ECG abnormalities have already been described as highly prevalent in patients with signs of dilated cardiomyopathy at echocardiogram [12].

Overall, our observations strongly emphasize the potential application of mHealth technology and telemedicine, together with RDT, to improve access to diagnosis and treatment for $\mathrm{CD}$ and $\mathrm{CChC}$ in remote areas of the rural Bolivian Chaco. In fact, although a pilot study, simultaneous screening by CSP and D-Heart electrocardiograph resulted feasible, with a cost/patient $<10 \$$ to start up.

The combined, on-field use of RDT and ECG in large-scale screening campaigns could play a pivotal role within a more comprehensive strategy against CD. Early diagnosis of $\mathrm{CD}$ is of paramount importance to start treatment before symptoms progress. In remote regions, easy-to-use RDTs, which use whole blood from digital puncture as sample, would ease access to CD diagnosis, allowing timely treatment.

Recently, the use of combined RDTs was shown to be a reliable and accurate alternative to conventional serological assays in order to achieve a conclusive CD diagnosis, in settings where equipped labs and trained personnel are not available [13].

The role of antitrypanosomal treatment in adult patients with established CChC remains controversial. So far, the only published placebo-controlled trial in adults with advanced $\mathrm{CChC}$ concluded that benznidazole treatment did not affect the clinical progression of Chagas cardiomyopathy, but important methodological bias has been raised [16,17]. Ideally, etiological treatment should be offered timely in adult patients with chronic Chagas disease before established cardiac damage requires more aggressive management [18,19]. Furthermore, recently published studies support benznidazole use in standard treatment in addition to new alternative regimens for short-course and combination treatments [20].

Screening campaigns that result in early therapy inception are, however, successful as long as effective vector control activities can be achieved, and intensive care be delivered to individuals in need.

As a case in point, in 2013, blanket insecticide application was shown to decrease the force of infection in the Bolivian Chaco, though active transmission remained [3,21,22]. Moreover, several pharmacological and non-pharmacological interventions are currently available and have been increasingly used in CChC patients with the intention of preventing or delaying complications [23].

As part of the study protocol, ECG recordings were sent to Florence for analysis. It is tempting to hypothesize that, should combined (ECG and RDTs) screening programs be further implemented, ECGs could be seamlessly transmitted to local cardiologists or community physicians with the intention to monitor individuals through time and create electrocardiographic and serologic 'profiles' to detect conversion (Figure 2A,B). 

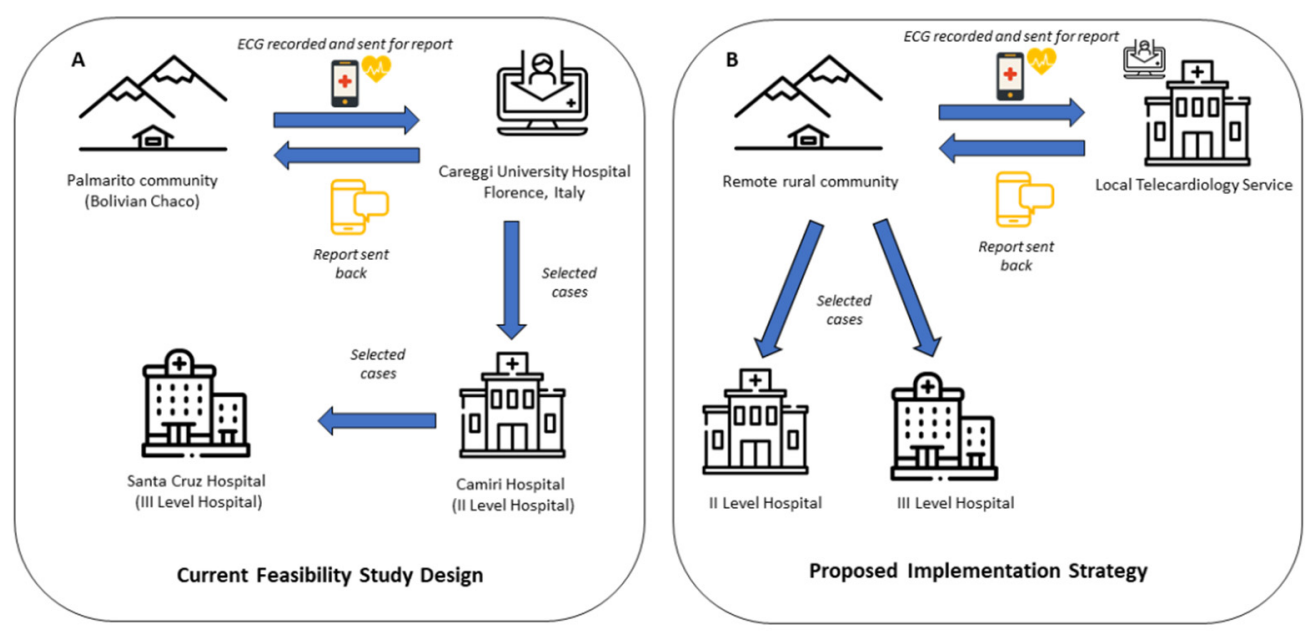

Figure 2. Current Study Design and Proposed on site implementation strategy. (A) Current study design is summarized. Specifically, patients are screened on site, in a community of the Bolivian Chaco. ECGs are sent to Telecardiology Service in Careggi University Hospital, Italy and reports are back on site; in case of need, patients with a pathologic ECG were recalled back in the community and referred to the nearest second level Hospital in Camiri (distance $80 \mathrm{~km}$ ). Patients requiring higher level of care were further referred to a III level Hospital in Santa Cruz (distance $250 \mathrm{~km}$ ). (B) Proposed implementation strategy is described. Patients are screened on site and ECGs are sent to a local telecardiology service; in case of need, patients with a pathologic ECG are recalled back in the community and referred to a second or third level Hospital, according to their condition.

Finally, pocket echocardiography integrated mHealth device assessments are now under scrutiny for potential applications in resource-limited settings. In a randomized trial enrolling 253 patients at a tertiary care center in Bangalore, India, patients who were randomly allocated to a $\mathrm{m}$-health clinic for valvular and structural heart disease, as opposed to standard of care, were associated with shorter time to definitive therapy [24].

In this scenario, adding such instruments to $C D$ screening would allow to reduce lag from infection to diagnosis, increase access to therapy and improve outcomes in patients with signs compatible with early cardiomyopathy, thus limiting disease progression and morbidity.

Ultimately, our effort may focus on bringing high-tech instruments at low-cost for effective remote screening therefore allowing for appropriate and timely diagnosis.

The study has limitations. The healthy volunteers were not randomly selected, but consecutively enrolled in the Health Centre. Severely ill community residents may have been unable to report to the health Centre for evaluation. Moreover, screening for $\mathrm{CD}$ was made on a single RDT, namely, CSP assay, which is in use as standard tool for Chagas disease screening by the Chagas National Program since 2005 and showed an excellent performance in the same geographical area $[13,14]$. Only people with potential CD-related ECG abnormalities $(n=22)$ were referred to a secondary level hospital for further investigations, including serology confirmation by ELISA testing. People with positive CSP, but normal ECG findings, were referred to the Chagas National Program for serological confirmation and were offered benznidazole treatment, but such data were not collected, being beyond the objective of the study.

\section{Conclusions}

Early diagnosis of $\mathrm{CD}$ and $\mathrm{CChC}$ is of paramount importance to provide access to targeted therapy (currently $<1 \%$ of all seropositive subjects) and maximize treatment benefits. Combined mHealth and RDTs may prove reliable and effective low-cost strategies, especially in rural, highly endemic environments like the Bolivian Chaco, to identify patients at high risk of disease and in need of further cardiologic assessment. Further 
studies are clearly needed to assess if these theoretical advantages are supported by patientcentered outcomes and positive cost-benefit analysis.

Author Contributions: Conceptualization, M.S. (Michele Spinicci), C.F., N.M., M.R., I.O. and A.B.; methodology, M.S. (Michele Spinicci), C.F., N.M., M.R., I.O. and A.B.; validation, H.G., R.V., M.S. (Marianne Strohmeyer), I.O. and A.B.; formal analysis, M.S. (Michele Spinicci), C.F. and N.M.; investigation, E.G., M.R. and V.P.; resources, N.M., H.G., M.S. (Marianne Strohmeyer), V.P. and R.V.; data curation, M.S. (Michele Spinicci), C.F., N.M., V.P. and E.G.; writing-original draft preparation, M.S. (Michele Spinicci), C.F. and N.M.; writing-review and editing, M.S. (Michele Spinicci), C.F., N.M., I.O. and A.B.; supervision, H.G., R.V., I.O. and A.B. All authors have read and agreed to the published version of the manuscript.

Funding: The study was supported by grants from the Regione Toscana (Italy), Progetti di Iniziativa Regionale (PIR) 2015 ('Supporto al miglioramento della condizione di salute della popolazione del Chaco Boliviano') and by funds from the Ministry of Education, University and Research (Italy) Excellence Departments 2018-2022 (Project for the Department of Experimental and Clinical Medicine). D-Heart srl, manufacturer of the device, provided smartphones, ECG devices and electrodes for the study.

Institutional Review Board Statement: The study was conducted according to the guidelines of the Declaration of Helsinki, and approved by a local Ethics Committee (Colegio Médico de Santa Cruz, TDEM CITE No. 008/2018).

Informed Consent Statement: Informed consent was obtained from all subjects involved in the study.

Data Availability Statement: The data presented in this study are available on request from the corresponding author.

Acknowledgments: We are grateful to Father Tarcisio Ciabatti, Sister Maria Bettinsoli and Francesco Cosmi (Convenio Ministerio de Salud-Vicariato de Camiri) for their support in carrying out this study and to the students of the Escuela de Salud del Chaco, Tekove Katu, Gutierrez, for their valuable assistance during the fieldwork. Finally, we would also like to thank the inhabitants of the communities for participating in the study. We acknowledge Lizzet Gil Nery (Head of Diagnostics for the Santa Cruz Departmental Chagas Program) for her valuable support in confirming CD diagnosis through ELISA test among participants with positive RDT and suspected Chagas-related cardiac alterations.

Conflicts of Interest: N.M. owns shares of the social vocation start-up D-Heart srl. The other authors declare no conflicts of interest. The funders had no role in the design of the study; in the collection, analyses, or interpretation of data; in the writing of the manuscript; or in the decision to publish the results.

\section{References}

1. World Helath Organization (WHO). Integrating Neglected Tropical Diseases into Global Health and Development: Fourth WHO Report on Neglected Tropical Diseases; World Health Organization: Geneva, Switzerland, 2017. Available online: https://apps.who.int/ iris/handle/10665/255011 (accessed on 1 August 2021).

2. Rassi, A.J.; Rassi, A.; Marin-Neto, J.A. Chagas disease. Lancet 2010, 375, 1388-1402. [CrossRef]

3. Samuels, A.M.; Clark, E.H.; Galdos-Cardenas, G.; Wiegand, R.E.; Ferrufino, L.; Menacho, S.; Gil, J.; Spicer, J.; Budde, J.; Levy, M.Z.; et al. Epidemiology of and Impact of Insecticide Spraying on Chagas Disease in Communities in the Bolivian Chaco. PLoS Negl Trop Dis. 2013, 7, e2358. [CrossRef] [PubMed]

4. Spinicci, M.; Gabrielli, S.; Rojo, D.; Gamboa, H.; Macchioni, F.; Mantella, A.; Lara, Y.; Villagrán, A.L.; Roselli, M.; Strohmeyer, M.; et al. Trypanosoma cruzi infection in the human population of the Bolivian Chaco: Four serosurveys over a 26-year period (1987-2013). J. Infect. Dev. Ctries 2020, 14, 199-206. [CrossRef]

5. Rassi, A.; Rassi, A.; Little, W.C.; Xavier, S.S.; Rassi, S.G.; Rassi, A.G.; Rassi, G.G.; Hasslocher-Moreno, A.; Sousa, A.S.; Scanavacca, M.I. Development and Validation of a Risk Score for Predicting Death in Chagas' Heart Disease. N. Engl. J. Med. 2006, 355, 799-808. [CrossRef] [PubMed]

6. $\quad$ Rojas, L.Z.; Glisic, M.; Pletsch-Borba, L.; Echeverría, L.E.; Bramer, W.M.; Bano, A.; Stringa, N.; Zaciragic, A.; Kraja, B.; Asllanaj, E.; et al. Electrocardiographic abnormalities in Chagas disease in the general population: A systematic review and meta-analysis. PLoS Negl. Trop. Dis. 2018, 12, 1-20. [CrossRef]

7. Benziger, C.P.; do Carmo, G.A.L.; Ribeiro, A.L.P. Chagas Cardiomyopathy: Clinical Presentation and Management in the Americas. Cardiol. Clin. 2017, 35, 31-47. [CrossRef] 
8. Vannucchi, V.; Tomberli, B.; Zammarchi, L.; Fornaro, A.; Castelli, G.; Pieralli, F.; Berni, A.; Yacoub, S.; Bartoloni, A.; Olivotto, I. Chagas disease as a cause of heart failure and ventricular arrhythmias in patients long removed from endemic areas: An emerging problem in Europe. J. Cardiovasc. Med. (Hagerstown) 2015, 16, 817-823. [CrossRef]

9. Bastawrous, A.; Armstrong, M.J. Mobile health use in low-and high-income countries: An overview of the peer-reviewed literature. J. R. Soc. Med. 2013, 106, 130-142. [CrossRef]

10. Maurizi, N.; Faragli, A.; Imberti, J.; Briante, N.; Targetti, M.; Baldini, K.; Sall, A.; Cisse, A.; Berzolari, F.G.; Borrelli, P.; et al. Cardiovascular screening in low-income settings using a novel 4-lead smartphone-based electrocardiograph (D-Heart). Int. J. Cardiol. 2017, 236, 249-252. [CrossRef]

11. Maurizi, N.; Fumagalli, C.; Cecchi, F.; Olivotto, I. Use of Smartphone-operated ECG for home ECG surveillance in COVID-19 patients. Eur. Heart J. Digit. Health 2021, 2, 175-178. [CrossRef]

12. Fernandez, A.B.; Nunes, M.C.; Clark, E.H.; Samuels, A.; Menacho, S.; Gomez, J.; Bozo, G.R.W.; Crawford, T.C.; Gilman, R.H.; Bern, C. Electrocardiographic and Echocardiographic Abnormalities in Chagas Disease Findings in Residents of Rural Bolivian Communities Hyperendemic for Chagas Disease. Glob. Heart 2015, 10, 159-166. [CrossRef]

13. Egüez, K.E.; Alonso-Padilla, J.; Terán, C.; Chipana, Z.; García, W.; Torrico, F.; Gascon, J.; Lozano-Beltran, D.F.; Pinazo, M.J. Rapid diagnostic tests duo as alternative to conventional serological assays for conclusive Chagas disease diagnosis. PLoS Negl. Trop. Dis. 2017, 11, 1-11. [CrossRef]

14. Chippaux, J.P.; Santalla, J.A.; Postigo, J.R.; Romero, M.; Salas, N.A.; Schneider, D.; Brutus, L. Sensitivity and specificity of chagas stat-pak ${ }^{\circledR}$ test in Bolivia. Trop. Med. Int. Health 2009, 14, 732-735. [CrossRef]

15. Ministerio de Salud y Deportes. Área del Programa Nacional de Control de Chagas. Available online: https://www.minsalud. gob.bo/38-libros-y-normas/fichas-bibliograficas/1575-area-chagas (accessed on 8 August 2021).

16. Morillo, C.A.; Marin-Neto, J.A.; Avezum, A.; Sosa-Estani, S.; Rassi, A.; Rosas, F.; Villena, E.; Quiroz, R.; Bonilla, R.; Britto, C.; et al. Randomized trial of benznidazole for chronic chagas' cardiomyopathy. N. Engl. J. Med. 2015, 373, 1295-1306. [CrossRef]

17. Rassi, A.; Marin-Neto, J.A.; Rassi, A. Chronic chagas cardiomyopathy: A review of the main pathogenic mechanisms and the efficacy of aetiological treatment following the BENznidazole evaluation for interrupting trypanosomiasis (BENEFIT) trial. Mem. Inst. Oswaldo Cruz. 2017, 112, 224-235. [CrossRef]

18. Viotti, R.; Alarcón de Noya, B.; Araujo-Jorge, T.; Grijalva, M.J.; Guhl, F.; López, M.C.; Ramsey, J.M.; Ribeiro, I.; Schijman, A.G.; Sosa-Estani, S.; et al. Towards a paradigm shift in the treatment of chronic chagas disease. Antimicrob. Agents Chemother. 2014, 58, 635-639. [CrossRef]

19. Dias, J.C.; Ramos, A.N.; Gontijo, E.D.; Luquetti, A.; Shikanai-Yasuda, M.A.; Coura, J.R.; Torres, R.M.; Melo, J.R.; Almeida, E.A.; Oliveira, W.; et al. 2nd Brazilian Consensus on Chagas disease, 2015. Rev. Soc. Bras. Med. Trop. 2016, 49, 3-60. [CrossRef] [PubMed]

20. Torrico, F.; Gascon, J.; Ortiz, L.; Alonso-Vega, C.; Pinazo, M.J.; Schijman, A.; Almeida, I.C.; Alves, F.; Strub-Wourgaft, N.; Ribeiro, I. Treatment of adult chronic indeterminate Chagas disease with benznidazole and three E1224 dosing regimens: A proof-of-concept, randomised, placebo-controlled trial. Lancet Infect. Dis. 2018, 18, 419-430. [CrossRef]

21. Gürtler, R.E. Sustainability of vector control strategies in the Gran Chaco Region: Current challenges and possible approaches. Mem. Inst. Oswaldo Cruz. 2009, 104, 52-59. [CrossRef]

22. Ministerio de Salud. Estado Plurinacional de Bolivia. Epidemiologic Yearbook 2016; Dirección General de Servicios de Salud-Unidad de Epidemiología-Ministerio de Salud: La Paz, Bolivia, 2017.

23. Rassi, A.; Dias, J.C.P.; Marin-Neto, J.A.; Rassi, A. Challenges and opportunities for primary, secondary, and tertiary prevention of Chagas' disease. Heart 2009, 95, 524-534. [CrossRef]

24. Bhavnani, S.P.; Sola, S.; Adams, D.; Venkateshvaran, A.; Dash, P.K.; Sengupta, P.P.; ASEF-VALUES Investigators. A Randomized Trial of Pocket-Echocardiography Integrated Mobile Health Device Assessments in Modern Structural Heart Disease Clinics. JACC Cardiovasc. Imaging 2018, 11, 546-557. [CrossRef] [PubMed] 